\title{
Mast cell and histamine content of human bronchoalveolar lavage fluid
}

\author{
RAYMOND M AGIUS, RICHARD C GODFREY, STEPHEN T HOLGATE
}

From Medicine I, Southampton General Hospital, Southampton

ABSTRACT Bronchoalveolar lavage was performed in 97 patients including control patients with bronchial carcinoma (24) and patients with sarcoidosis (20), cryptogenic fibrosing alveolitis (9), and asthma (4), and others. Cytocentrifuged slides were stained by two methods: May-Grünwald Giemsa and toluidine blue. In the last 32 subjects the bronchoalveolar lavage fluid was separated into supernatant and cell pellet for the subsequent assay of the preformed mast cell mediator, histamine. Comparison of the two methods of staining showed a bias towards toluidine blue. Controls had a differential mean (SE) mast cell count of $0.07 \%(0.01 \%)$. Higher counts were noted in cryptogenic fibrosing alveolitis-0.61\% $(0.15 \%)(\mathrm{p}<0.001)$-and in sarcoidosis$0.14 \%(0.02 \%)(p<0.05)$. There was a strong correlation between absolute mast cell counts and cell lysate histamine concentration $(r=0.78, p<0.001)$. Less strong, but significant, correlations between supernatant histamine concentration and absolute mast cell counts $(\mathrm{r}=0.48, \mathrm{p}<0.01)$ or cell lysate histamine concentration $(r=0.72, p<0.01)$ were also found. Derived mean values of histamine per mast cell ranged from 3.7 to 10.9 picograms. The mean histamine content of lavage fluid supernatant as a percentage of the total lavage fluid histamine was $24.9 \%(3.3 \%)$. The possible clinical significance of these findings is discussed.

Human lungs are a particularly rich source of the vasoactive and bronchoactive amine histamine, which is almost entirely contained within the secretory granules of mast cells. Mast cells are located throughout the respiratory tract, both in the airways and in the alveoli. Within the distal airways they are mostly located beneath the respiratory epithelium superficial to the basement membrane, ${ }^{1}$ although occasionally they are observed between epithelial cells and may abut directly on to the bronchial lumen. ${ }^{2}$ Mast cells are also found in association with alveolar capillaries and form a component of the alveolar walls, where they constitute $1.6-2.1 \%$ of the surface area. ${ }^{3}$ Not surprisingly therefore mast cells and basophil like cells have been identified in bronchoalveolar lavage fluid ${ }^{4}$ and presumably originate from both the distal conducting airways and the alveoli.

Mast cell hyperplasia in the human gastrointestinal tract has been found in the chronic inflammation

Address for reprint requests: Dr RM Agius, Medicine I, Centre Block, Southampton General Hospital, Southampton SO1 4XY.

Accepted 15 April 1985 of Crohn's disease ${ }^{5}$ and gluten enteropathy ${ }^{6}$ and accompanying parasitic infections. ${ }^{7}$ In fibrotic lung diseases mast cell numbers have been shown to be increased in the pulmonary parenchyma and their appearances suggest partial degranulation, which might contribute to continuing alveolar injury. ${ }^{8}$ In support of this, bleomycin induced injury to the pulmonary parenchyma of rodents stimulates up to 10 fold increases in mast cell numbers and 14 fold increases in tissue histamine. ${ }^{9}$

Mast cells may be activated by several mechanisms to secrete preformed and newly generated mediators, which have potent inflammatory properties. By analogy with animal models of antigen induced bronchoconstriction, ${ }^{1011}$ it is probably those mast cells adjacent to the airway lumen that are activated by inhaled provoking agents. These mast cells are likely to play a sentinel role in the ensuing inflammatory response, which is a characteristic pathological feature of airway diseases such as asthma ${ }^{12}$ and chronic bronchitis.'

Systematic cytological investigation of bronchoalveolar lavage fluid has usually not included examination of mast cells. ${ }^{13}$ Since there has been little investigation of mast cells and histamine reco- 
vered from lavage fluid in man, ${ }^{414} 15$ we undertook a study of differential mast cell counts in lavage fluid from patients with clinical indications for fibreoptic bronchoscopy. Mast cells were identified both cytochemically and by their content of histamine. This enabled the amount of histamine per mast cell to be calculated and the relationship between mast cell counts and individual diseases to be studied.

\section{Methods}

\section{PATIENTS}

We studied 97 patients who had a clinical indication for fibreoptic bronchoscopy (table 1). They were undergoing this procedure either because of suspected neoplasia or as part of the investigation of interstitial lung disease. There were 77 men and 20 women and their mean age was 56 years (range 19-76). The histological diagnoses in 53 patients were bronchial carcinoma (24), sarcoidosis (20), and cryptogenic fibrosing alveolitis (9). In addition, four patients with a clinical diagnosis of asthma were studied (the indication for bronchoscopy being haemoptysis in one and pulmonary shadowing in three). Three of the asthmatic patients were receiving regular corticosteroid treatment (inhaled beclomethasone dipropionate in two and oral prednisolone in one). The remaining asthmatic patient was treated with regular $\beta_{2}$ adrenoceptor agonists only. The diagnoses in the remaining patients are shown in table 1 . Subjects gave their informed consent for the procedure and the study was approved by the Southampton University and hospital ethical committee.

\section{BRONCHOALVEOLAR LAVAGE}

The lavage technique was adapted from that of Cole et al. ${ }^{16}$ After premedication with intramuscular atropine and either intramuscular papaveretum or

Table 1 Diagnoses in the 97 patients studied

\begin{tabular}{ll}
\hline Diagnosis & No of cases \\
\hline Unilateral primary carcinoma of the lung & 24 \\
Sarcoidosis & 20 \\
Cryptogenic fibrosing alveolitis & 9 \\
Bronchial asthma* & 4 \\
Others & 15 \\
No abnormality found & 7 \\
Chronic bronchitis $\dagger$ & 6 \\
Other neoplasms & 4 \\
Infection & 4 \\
Pulmonary fibrosis, histologically undiagnosed & 2 \\
Haemosiderosis & 1 \\
Eosinophilic pneumonia & 1 \\
Extrinsic allergic alveolitis & \\
\hline
\end{tabular}

${ }^{*}$ Mean $\%$ predicted $\mathrm{FEV}_{1}: 65 \%$, range $32-91 \%$.

†Mean $\%$ predicted FEV,: $71 \%$, range $43-83 \%$. intravenous midazolam, followed by $2 \%$ lignocaine for airway local anaesthesia, the fibreoptic bronchoscope (Olympus BF3 or 4B2) was wedged into a basal subsegment of the lung on the side contralateral to the proposed bronchoscopic biopsy site. Sterile bicarbonate buffered saline ( $\mathrm{pH} 7.4)$, prewarmed to $37^{\circ} \mathrm{C}$, was introduced through the side arm of the bronchoscope in three to five aliquots of $50 \mathrm{ml}$ each followed by gentle aspiration. The aspirated lavage fluid was collected into a siliconised glass bottle precooled to $4^{\circ} \mathrm{C}$. The lavage fluid was filtered through $60 \mu \mathrm{m}$ mesh gauze to remove mucus and cell aggregates. In nine lavages the residual material recovered from the filter microscopically consisted of mucus with entrapped epithelial cells, bacteria, and inflammatory cells with a lower trypan blue exclusion than those in the filtrate. The residue was associated with a mean (SE) of $7.1 \%(2.1 \%)$ of the total lavage fluid histamine. An aliquot of the filtered cell suspension was removed for counting of unstained nucleated cells, an improved Neubauer counting chamber being used. The remaining cell suspension was centrifuged at $300 \mathrm{~g}$ for 10 minutes to separate the cells and supernatant. The cell pellet was washed in buffered saline and aliquots were centrifuged on to glass microscope slides with a cytocentrifuge (Shandon Elliott Cytospin). In the last 32 subjects the lavage fluid supernatant was retained for assay of cell free histamine. Aliquots of the corresponding cell pellets were lysed by freeze thawing and reconstituted in physiological saline for assay of cell associated histamine.

\section{CELL STAINING AND COUNTING}

At least one cytocentrifuged slide from each bronchoalveolar lavage was fixed and stained with May-Grünwald Giemsa. One thousand nucleated cells from randomly coded slides were examined and differential counts were made of the macrophages, lymphocytes, neutrophils, eosinophils, mast cells, and epithelial cells. At least one further cytocentrifuged slide from each lavage was stained unfixed in $0.5 \%$ toluidine blue in 0.5 molar hydrochloric acid for 30 minutes. ${ }^{17}$ In a study of seven cytocentrifuged preparations of lavage fluid prior fixation with Carnoy's fixative did not give significantly different mast cell counts. In view of the low mast cell counts, advantage was taken of the metachromasia of mast cells stained with toluidine blue, differentiating them from other nucleated cells. In an evenly distributed cytocentrifuged preparation (randomly coded) the total nucleated cells were counted in five fields (with a 40 fold magnification of the objective lens) and the mean cell number per field was calculated. The mast cells were counted in consecutive 
fields up to a total of about 10000 nucleated cells and differential counts expressed as a percentage of the total. The intraobserver coefficient of variation was $17 \%$.

\section{ASSAYS}

Histamine was assayed in bronchoalveolar lavage fluid supernatants and cell pellets by a microenzymatic single isotope radiotransfer assay using partially purified rat kidney histamine methyltransferase. The interassay and intra-assay coefficients of variation of this assay were $11 \%$ and $7 \%$ respectively, and the limit of histamine detection was $0.08 \mathrm{ng} / \mathrm{ml} .^{18}$ Histamine contents were expressed in ng histamine per $\mathrm{ml}$ of lavage supernatant and per $\mathrm{ml}$ of cell lysate corrected to the original volume from which the pellet was derived. Albumin in the lavage fluid supernatants retained for histamine assay was assayed by a modified immunoturbidimetric method. ${ }^{19}$

\section{STATISTICS}

Since the groups of patients were not matched for age or sex, differences in mast cell counts were analysed by means of the Mann-Whitney $U$ test. The two staining techniques used to identify mast cells were compared by calculating the difference between percentage counts for the two techniques for each lavage fluid sample. The mean of these differences is the relative bias and their standard deviation is the estimate of error. ${ }^{20}$ The relationships between lavage fluid mast cell counts and cell associated and cell free histamine contents were established by unweighted and power least squares regression analyses. From the slope and intercept of these regression lines the theoretical mast cell content of histamine was calculated.

\section{Results}

No adverse reactions were observed during or after bronchoalveolar lavage in any of the patients studied. The mean (SE) volume of lavage fluid recovered from the instilled buffered saline was $39.6 \%$ $(1.3 \%)$ and it contained $2.4(0.5) \times 10^{7}$ nucleated cells.

The mast cells were identified on slides stained with May-Grünwald Giemsa by the metachromasia of their cytoplasmic granules. Metachromasia was more obvious with toluidine blue (fig 1 ), which stained the mast cell granules red violet, contrasting with the faint orthochromatic staining of other nucleated cells. There was considerable heterogeneity of mast cell size and metachromasia observed with both stains. Rarely small extracellular clumps of metachromatic material were noted, and
Fig 1 Photomicrograph of cytocentrifuged preparation of bronchoalveolar lavage cells from a patient with cryptogenic fibrosing alveolitis stained with toluidine blue. The mast cells contrast well with the other cells. $(\times 540$. $)$

occasionally weakly metachromatic material was present in cells with obvious macrophage morphology (large size, small nuclear to cytoplasmic ratio, and smokers' inclusions). In the latter case the metachromatic material was faint, irregular, and atypically clumped or vacuolated rather than granular. These cells were not counted as mast cells. Epithelial cells constituted, on average, less than 3\% of the total nucleated cell population.

While mast cells could be identified by both staining techniques, toluidine blue was more sensitive especially at low mast cell differential counts. Thus when the May-Grünwald Giemsa method was used no counts were scored in 57 lavage fluid samples but mast cells were seen with toluidine blue in all except six of these. Comparison of the two methods showed an error of $0.15 \%$ and a bias towards toluidine blue of $0.075 \%$. In view of the greater sensitivity provided by toluidine blue for the counting of mast cells, this stain was used in subsequent correlations with diseases and histamine contents. Mast cell counts expressed as percentages of the total nucle- 


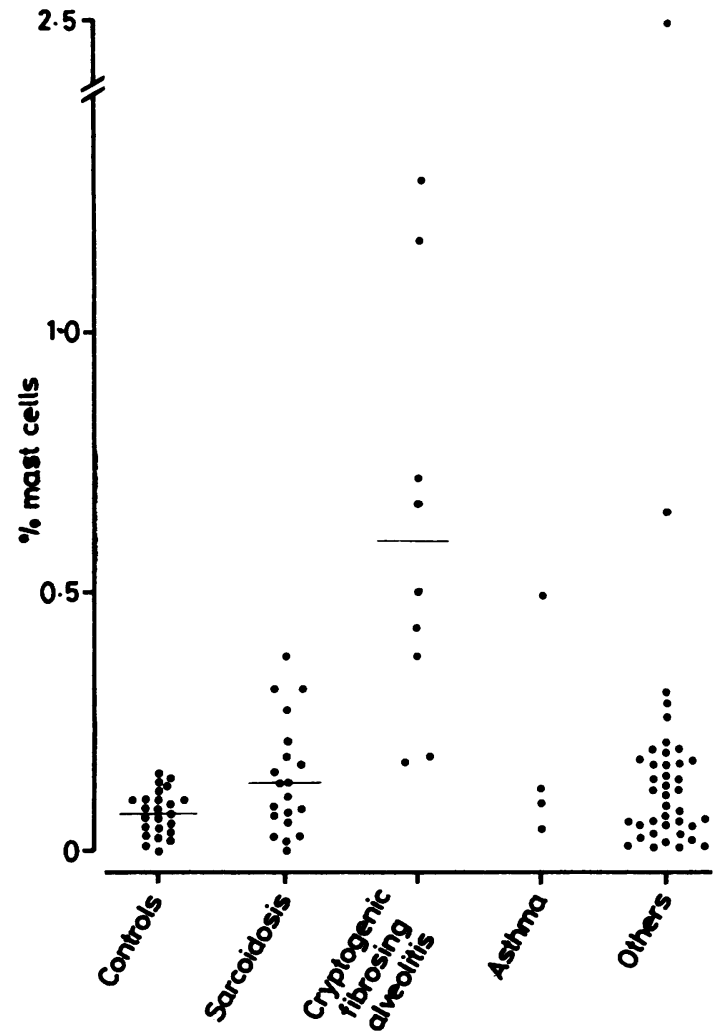

Fig 2 Diffrential mast cell counts in bronchoalveolar capressed as percentages of the total nucleated cells. Controls (carcinoma) < sarcoidosis $(p<0.05)$; controls $<$ cryptogenic fibrosing alveolitis $(p<0.001)$; sarcoidosis $<$ cryptogenic fibrosing alveolitis $(p<0.001)$.

ated cells ranged from zero to $2.5 \%$. More detailed analysis showed that increased mast cell counts were encountered in association with particular diseases (fig 2). The mean (SE) differential mast cell count from the contralateral lungs of those patients with histologically proved bronchial carcinoma (controls) was $0.07 \%(0.01 \%)$. In the 20 patients with sarcoidosis the mean mast cell count was $0.14 \%$ $(0.02 \%)$, which was significantly higher $(p<0.05)$ than that of the controls. In the nine subjects with cryptogenic fibrosing alveolitis a mean differential mast cell count of $0.61 \%(0.15 \%)$ was significantly higher than that of either the control patients $(p<$ $0.001)$ or those with sarcoidosis $(p<0.001)$. Three asthmatic patients who had been treated with corticosteroids had a mean differential mast cell count of $0.085 \%$, which was not different from that of control patients. The one asthmatic subject who had not received corticosteroid treatment (but who also had pulmonary eosinophilia) had an increased differential mast cell count of $0.5 \%$. The highest differential mast cell count, $2.5 \%$, was encountered in a patient with extrinsic allergic alveolitis related to exposure to avian proteins.

In the last 32 patients who underwent bronchoalveolar lavage the relationship between mast cell numbers and the histamine content of the cell pellet and supernatant was investigated. The group included six patients with carcinoma, six with sarcoidosis, five with cryptogenic fibrosing alveolitis, and four with asthma. For this heterogeneous group the number of mast cells recovered per $\mathrm{ml}$ of returned lavage fluid ranged from 10 to 6000 . The histamine content of lysed cell pellets was always above the limit of detection of the assay. A significant positive correlation was observed between mast cell counts and cell associated histamine when analysis was by unweighted linear regression $(\mathrm{r}=0.71, \mathrm{p}<0.001 ; y=0.0037 x-1.054)$. From the slope of the regression line the mean histamine content per mast cell was $3.7 \mathrm{pg}$. An improved correlation was observed when the data were analysed by a power regression $(r=0.78, p<0.001)$ (fig 3 ). The intercept corresponded to a histamine content of $9.8 \mathrm{pg}$ per mast cell. For each lavage sample the histamine content per mast cell ranged from 0.8 to $42.4 \mathrm{pg}$; the geometric mean of these 32 values was $10.9 \mathrm{pg}$ and the arithmetic mean was $7.5(1.4) \mathrm{pg}$.

Eight of the 32 lavage fluid supernatant histamine concentrations were at the limit of detection of the histamine assay (that is, $0.08 \mathrm{ng} / \mathrm{ml}$ ) while the high-

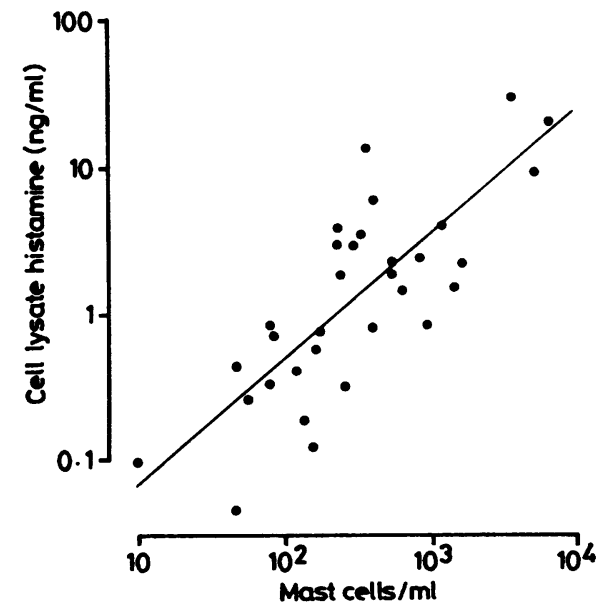

Fig 3 Relationship between cell pellet lysate histamine and absolute mast cell counts analysed by power regression. $(r=0.78, p<0.001)$. 

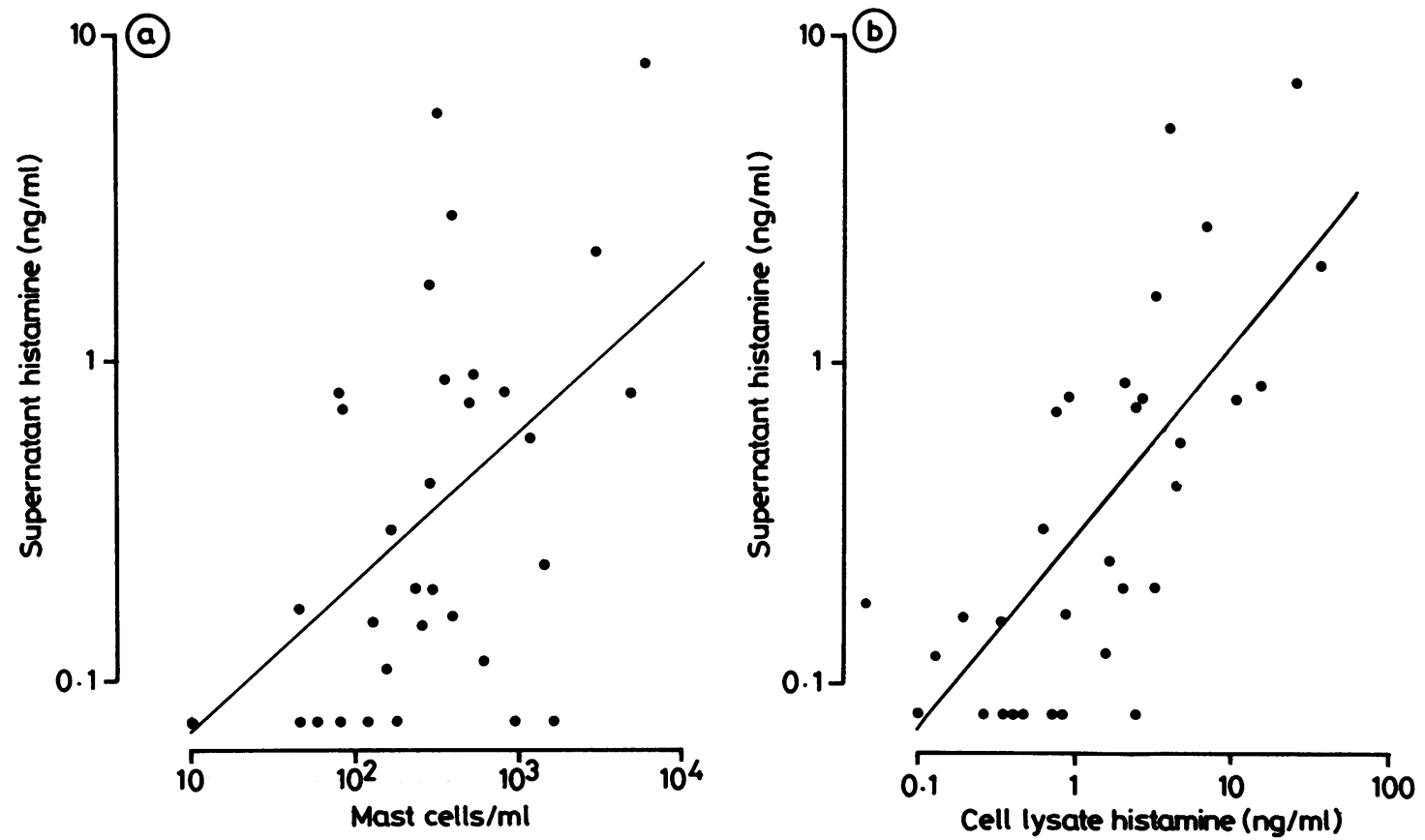

Fig 4 (a) Relationship between supernatant histamine concentration and absolute mast cell counts analysed by power regression $(r=0.48, p<0.01)$. (b) Relationship between supernatant histamine concentration and lysed cell pellet histamine content analysed by power regression $(r=0.57, p<0.01)$.

est value was $8 \mathrm{ng} / \mathrm{ml}$. The supernatant histamine concentrations correlated weakly with mast cell counts when analysed by unweighted $(\mathrm{r}=0.59, \mathrm{p}<$ $0.01 ; y=0.0007 x+0.34)$ or power $(\mathrm{r}=0.48, \mathrm{p}<$ 0.01) regression (fig $4 a$ ). A correlation was also established between cell associated and cell free histamine by unweighted linear $(\mathrm{r}=0.57, \mathrm{p}<0.01 ; y$ $=0.14 x+0.37)$ and power regression $(\mathrm{r}=0.72, \mathrm{p}$ $<0.01$ ) (fig 4b). The histamine content of lavage fluid supernatant as a percentage of the total lavage fluid histamine ("spontaneous release") was $24.9 \%$ $(3.3 \%)$. No significant difference could be found between spontaneous histamine releases and various disease groups. Table 2 shows the values for differential mast cell counts, mean mast cell histamine, supernatant histamine concentration, and supernatant albumin concentration analysed according to the individual diseases studied. Patients with cryptogenic fibrosing alveolitis and asthma had a tendency towards a lower mean mast cell histamine content than that of controls and a correspondingly higher supernatant histamine concentration. These differences, however, were not significant. There was no significant relationship between the mast cell content of lavage fluid and the number of lymphocytes, neutrophils, or eosinophils in the con-

Table 2 Comparison of differential mast cell counts and mean mast cell histamine, supernatant histamine, and supernatant albumin concentration in lavage fuid from patients in the principal diagnostic groups (values are means with standard errors in parentheses)

\begin{tabular}{lcccc}
\hline & $\begin{array}{l}\text { Carcinoma } \\
\text { (controls) }\end{array}$ & Sarcoidosis & CFA & Asthma \\
\hline No of cases (n) & 6 & 6 & 5 & 4 \\
Differential mast cell counts (\%) & $0.088(0.015)$ & $0.24(0.045) \dagger$ & $0.71(0.22) \dagger$ & $0.19(0.11)$ \\
Mean histamine per mast cell (pg) & $12.5(4.5)$ & $14.7(7.0)$ & $6.8(3.0)$ & $5.2(1.1)$ \\
Supernatańt histamine (ng/ml) & $0.32(0.13)$ & $0.33(0.12)$ & $1.3(0.48)$ & $2.5(1.8)$ \\
Supernatant álbumin (mg/l) & $65.9(16.0)$ & $142.6(31.3)^{*}$ & $83(17.2)^{*}$ & $125.5(53.1)$ \\
\hline
\end{tabular}

*n -1 .

+Significant difference from controls $(p<0.05)$ by Mann Whitney $U$ test.

CFA-cryptogenic fibrosing alveolitis. 
trols or patients with cryptogenic fibrosing alveolitis. In the patients with sarcoidosis, however, a significant correlation existed between mast cell and neutrophil counts $(r=0.48, p<0.05)$, but not between mast cell and lymphocyte counts.

\section{Discussion}

This study confirms the presence of mast cells and the mast cell granule marker histamine in lavage fluid from subjects with a wide variety of pulmonary diseases. Furthermore, we have been able to establish a relationship between increased mast cell numbers and certain pulmonary diseases in which mast cells may play a pathogenetic role. Positive correlations found between mast cell numbers and cell associated and cell free histamine enabled calculation of the histamine content of lavage fluid mast cells and the "spontaneous" release of histamine.

Patterson et $a l^{21}$ were the first to describe the presence of basophils and mast cells in bronchial lavage fluid, where a range of $0.36-0.7 \%$ was reported. In their study they described a high proportion of epithelial cells recovered from the lavage fluid (38\% of nucleated cells), which probably reflected epithelial trauma to the airways during the lavage procedure and therefore could lead to erroneously high mast cell counts. The values for differential mast cell counts found in our controls $(0.07 \%)$, in whom contralateral tumour free segments of lung were lavaged, were similar to those of Tomioka et al ${ }^{4}$ who reported differential counts of $0.08 \%$ when mast cells were identified both by their metachromasia with toluidine blue and by the presence of cell surface IgE demonstrated by an immunofluorescent technique. The stains used in the present study were chosen because May-Grünwald Giemsa is a widely used general purpose stain used in cytological studies of bronchoalveolar lavage fluid and toluidine blue is a widely used stain to identify mast cells at mucosal surfaces or in connective tissue by granule metachromasia..$^{91722}$ In a study still in progress we are obtaining differential mast cell counts for lavage fluid similar to those reported here when using either Carnoy's fixation followed by sequential staining with Alcian blue/Safranin $\mathrm{O}$ or acetone fixation followed by immunocytochemical staining for cell bound IgE. ${ }^{23}$

The precise origin of mast cells in bronchoalveolar lavage fluid is undecided. They may originate from both the bronchial epithelium and the alveoli. We have shown that in sarcoidosis and to a greater extent in cryptogenic fibrosing alveolitis mast cells were recovered in lavage fluid in greater numbers than in our control population. This suggests that a considerable proportion of mast cells in broncho- alveolar lavage fluid originate from the alveoli, which is the anatomical locus for these diseases. Haslam et al have reported increased supernatant histamine content in lavage fluid from patients with cryptogenic fibrosing alveolitis ${ }^{14}$ and also found increased mast cell differential counts in patients with extrinsic allergic alveolitis having bronchoalveolar lavage. ${ }^{15}$ It is of interest that in the present study the highest mast cell count $(2.5 \%)$ was observed in a patient with histologically proved avian granuloma. Kawanami ${ }^{8}$ has also shown that mast cell numbers are increased in the pulmonary parenchyma of patients with widely varying interstitial diseases associated with fibrosis. Despite small sample numbers, the finding of a low mast cell histamine content and a high supernatant histamine concentration in cryptogenic fibrosing alveolitis and asthma implies that in these diseases mast cells are in an active secretory state. These observations raise important questions relating to the possible role of mast cells in the pathogenesis of alveolitis and pulmonary fibrosis, whether this is idiopathic or caused by exogenous agents.

The recent finding ${ }^{24} 25$ that mast cell populations may increase in response to specific growth factors such as interleukin 3 from activated $T$ lymphocytes makes it possible that the increased number of mast cells found in biopsy specimens and bronchoalveolar lavage fluid from patients with parenchymal lung disease may have an active role in the inflammatory alveolitis. The positive correlation between differential neutrophil and mast cell counts in patients with established sarcoidosis might suggest an interaction between these two cell types in the evolution of interstitial lung disease. The precise relationship of mast cells to other cells recovered in bronchoalveolar lavage fluid, however, which may be of use in the assessment of various parenchymal lung diseases, ${ }^{26} 27$ awaits further clarification.

Of the four asthmatic patients in whom bronchoalveolar lavage was performed, three, who had been treated with corticosteroids, had mast cell differential counts within our control range. The one patient who had not received corticosteroid treatment had a mast cell count higher than our control range. Tomioka $e \mathrm{al}^{4}$ have reported increased numbers of mast cells recovered in bronchoalveolar lavage fluid from asthmatic patients not having corticosteroid treatment and they suggest that this may have aetiological significance.

Histamine is one of the major preformed mediators of the mast cell granule. A good correlation between mast cell counts and cell associated histamine concentration in bronchoalveolar lavage fluid found in our study enabled calculation of the histamine content of a mast cell. Values of 3.7- 
$10.9 \mathrm{pg}$ per mast cell correspond closely to values reported for mast cells dispersed from human lung tissue. ${ }^{28}$ This range is higher than that reported by Patterson $e^{t} a^{21}$ for mast cells from the bronchial lumen and for human basophils, but within the range found by Tomioka et al. ${ }^{4}$ The finding that the histamine content of bronchoalveolar lavage fluid cells correlated best with mast cell counts when a power regression was used to analyse the data (fig 3 ) suggests that, within individual patients and diseases, the mast cell content of histamine has a wide variation. Whether this reflects mast cell heterogeneity, in the sense of subpopulations of mast cells with different morphological, biochemical and pharmacological characteristics, awaits further study. The apparent morphological heterogeneity in terms of size and granule content of lavage mast cells is itself not good evidence for distinct subsets as it may represent varying cell maturity or degrees of activation. Morphological proof of heterogeneity would require the preparation and staining of cells by proved techniques closely matched for both lavage cells and control cell populations. Such important precautions must also hold true for functional comparisons with mast cells from other sources.

In the handling of mast cells from any source the possibility of loss of intracellular histamine through cell washing ${ }^{29}$ by lysis or activation is a matter for concern. Bronchoalveolar lavage handling does not require the mechanical or enzymatic dispersal of cells and so minimises the risk of loss of histamine from mast cells (which would result in an underestimate of mast cell histamine content and an overestimate of supernatant histamine). It remains possible, however, that a proportion of the lavage fluid supernatant could contain some histamine of bacterial origin. ${ }^{30}$ When lavage cells are challenged with the calcium ionophore A23187 or by reversed anaphylaxis with antihuman IgE most of the histamine that is physiologically accessible is released within the first two minutes of challenge, ${ }^{31}$ a time course that is more characteristic of mast cell than of basophil secretion. ${ }^{32}$ Release of histamine from bronchoalveolar lavage cells is closely paralleled by the generation of large amounts of prostaglandin $\mathrm{D}_{2},{ }^{31}$ a prostanoid produced by mast cells but not by basophils. ${ }^{32}$

The correlations between cell associated histamine and mast cell counts in our study were somewhat better than those reported by Tomioka $e t$ al. ${ }^{4}$ On the basis of the tabular data presented in their paper for 26 subjects studied, an unweighted linear regression of histamine content against mast cell numbers per $10^{6}$ nucleated cells give coefficients for a linear regression of $0.43(p<0.05)$ and for a power regression of $0.54(p<0.01)$. A better corre- lation found between these indices in our study is probably the result of the larger number of nucleated cells counted $(10000 \vee 3000)$ and because all our differential counts were carried out on dry permanent mounts. While we have also shown a significant correlation between the histamine content of bronchoalveolar lavage fluid supernatants and mast cell counts and cell associated histamine, the relationship between these measurements was not strong. Thus in our opinion it is difficult to draw useful conclusions regarding the contribution of mast cells to bronchoalveolar lavage fluid on the basis of cell free histamine measurements alone.

The ability to carry out bronchoalveolar lavage safely in selected patients should enable the further clarification of the role of mast cells in pulmonary diseases, although it is important to bear in mind the possible existence of heterogeneity among mast cells recovered by bronchoalveolar lavage, particularly with respect to their origin from the alveoli or airways.

We are grateful to Dr RK Knight for permitting us to study some of the control patients in this study and to Dr PJ Cole and the Wellcome Trust for facilities and financial support respectively in connection with the earlier part of this work. Dr DJF Rowe kindly performed the albumin assays and Mrs $M$ Dowling typed the manuscript.

\section{References}

1 Lamb D, Lumsden A. Intraepithelial mast cells in human airway epithelium: evidence for smokinginduced changes in their frequency. Thorax 1982; 37:334-42.

2 Jeffery PK, Corrin B. Structural analysis of the respiratory tract. In: Bienenstock J, ed. Immunology of the lung and upper respiratory tract. New York: McGraw-Hill, 1984:1-27.

3 Fox B, Bull TB, Guz A. Mast cells in the human alveolar wall: an electromicroscopic study. J Clin Pathol $1981 ; 34: 1333-42$.

4 Tomioka M, Ida S, Shindoh Y, Ishihara T, Takishima T. Mast cells in bronchoalveolar lumen of patients with bronchial asthma. Am Rev Respir Dis 1984; 129: 1000-5.

5 Dvorak AM. Mast cell hyperplasia and degranulation in Crohn's disease. In: Pepys J, Edwards AM, eds. The mast cell: its role in health and disease. Tunbridge Wells, Pitman Medical Publishing Co, 1979:657-62.

6 Strobel S, Busuttil A, Ferguson A. Human intestinal mucosal mast cells: expanded population in untreated coeliac disease. Gut 1983; 24:222-7.

7 Gustowska L, Ruitenberg EJ, Elgersma A, Kociecka W. Increase of mucosal mast cells in the jejunum of patients infected with Trichinella spiralis. Int Arch Allergy Appl Immunol 1983;71:304-8.

8 Kawanami O, Ferrans VJ, Fulmer JD, Crystal RG. Ultrastructure of pulmonary mast cells in patients with 
fibrotic lung disorders. Lab Invest 1979;40:717-34.

9 Goto T, Befus D, Low R, Bienenstock J. Mast cell heterogeneity and hyperplasia in bleomycin-induced pulmonary fibrosis of rats. Am Rev Respir Dis 1984;130:797-802.

10 Hogg JC. Bronchial mucosal permeability and its relationship to airways hyperreactivity. Eur J Respir Dis 1982; 63: 17-22.

11 Carswell F, Morrisey J. Antigenic penetration of the respiratory membrane in sensitised rats. J Physiol 1982;334:43P (abstract).

12 Holgate ST. The human lung mast cell: morphology, biochemistry and role in allergic asthma. In: Saunders KB, ed. Advanced medicine 19. London: Pitman Medical, 1983: 287-306.

13 Studdy PR, Rudd RM, Gellert AR, Uthayakumar S, Sinha G, Geddes DM. Bronchoalveolar lavage in the diagnosis of diffuse pulmonary shadowing. $\mathrm{Br} J \mathrm{Dis}$ Chest 1984;78:46-54.

14 Haslam PL, Cromwell O, Dewar A, Turner-Warwick $M$. Evidence of increased histamine levels in lung lavage fluids from patients with cryptogenic fibrosing alveolitis. Clin Exp Immunol 1981;44:587-93.

15 Haslam PL, Dewar A, Butchers P, Turner-Warwick M. Mast cells in bronchoalveolar lavage fluids from patients with extrinsic allergic alveolitis. Am Rev Respir Dis 1982;125, suppl:51.

16 Cole P, Turton C, Lanyon H, Collins J. Bronchoalveolar lavage for preparation of free lung cells: technique and complications. $\mathrm{Br} J$ Dis Chest 1980;74:273-8.

17 Enerback L. Mast cells in rat gastrointestinal mucosa. 2. Dye-binding and metachromatic properties. Acta Path Microbiol Scand 1966;66:303-12.

18 Church MK, Pao G J-K, Holgate ST. Characterisation of histamine secretion from mechanically dispersed human lung mast cells: effect of anti-IgE, calcium ionophore A23187, compound $48 / 80$ and basic polypeptides. J Immunol 1982;129:2116-21.

19 Rowe DJF, Hayward M, Bagga H, Betts P. Effect of glycaemic control and duration of disease on overnight albumin excretion in diabetic children. $\mathrm{Br} \mathrm{Med} J$ 1984; 289:957-9.

20 Altman DG, Bland JM. Measurement in medicine: the analysis of method comparison studies. Statistician 1983;32:307-17.

21 Patterson R, McKenna JM, Suszko IM, et al. Living histamine-containing cells from the bronchial lumen of humans. Description and comparison of histamine content with cells of rhesus monkeys. J Clin Invest 1977;59:217-25.

22 Wingren U, Enerback L. Mucosal mast cells of the rat intestine: a re-evaluation of fixation and staining properties, with special reference to protein blocking and solubility of the granular glycosaminoglycan. Histochem J 1983;15:571-82.

23 Agius RM, Jones D, Holgate ST. Staining characteristics of human. pulmonary mast cells. Thorax 1985; 40: 214 (abstract).

24 Nabel G. Galli SJ, Dvorak AM, Dvorak HK, Cantor $H$. Inducer $T$ lymphocytes synthesize a factor that stimulates proliferation of cloned mast cells. Nature 1981;291:332-4.

25 Nagao K, Yokoro K, Aaronson SA. Continuous lines of basophil/mast cells derived from normal mouse bone marrow. Science 1981;212:333-5.

26 Keogh BA, Hunninghake GW, Line BR, Crystal RG. The alveolitis of pulmonary sarcoidosis. Evaluation of natural history and alveolitis-dependent changes in lung function. Am Rev Respir Dis 1983;128:256-65.

27 Haslam PL, Turton CWG, Heard B, et al. Bronchoalveolar lavage in pulmonary fibrosis: comparison of cells obtained with lung biopsy and clinical features. Thorax 1980;35:9-18.

28 Schulman ES, Kagey-Sobotka A, MacGlashan DW, et al. Heterogeneity of human mast cells. J Immunol 1983;131: $1936-41$.

29 Saltini C, Hance AJ, Ferrans VJ, Basset F, Bitterman PB, Crystal RG. Accurate quantification of cells recovered by bronchoalveolar. lavage. Am Rev Respir Dis 1984;130:650-8.

30 Sheinman BD, Devalia JL, Davies RJ. Genesis of histamine in sputum: a role for bacteria in the airflow obstruction of acute exacerbations of chronic airways disease? Thorax 1985; 40: 238 (abstract).

31 Agius RM, Robinson C, Holgate ST. Release of histamine and newly generated mediators from human bronchoalveolar lavage cells. Thorax 1985;40:220-1 (abstract).

32 Schleimer RP, MacGlashan DW, Peters SP, et al. Inflammatory mediators and mechanisms of release from purified human basophils and mast cells. J Allergy Clin Immunol 1984;74:473-81. 